This item was submitted to Loughborough's Research Repository by the author.

Items in Figshare are protected by copyright, with all rights reserved, unless otherwise indicated.

\title{
Identifying what makes a good question in a mechanics diagnostic test
}

\section{PLEASE CITE THE PUBLISHED VERSION}

http://www.ingentaconnect.com/content/manup/ijmee/2008/00000036/00000003/art00009

\section{PUBLISHER}

(C) Manchester University Press

\section{VERSION}

AM (Accepted Manuscript)

\section{LICENCE}

CC BY-NC-ND 4.0

\section{REPOSITORY RECORD}

Lee, Stephen, Martin C. Harrison, and Carol L. Robinson. 2019. "Identifying What Makes a Good Question in a Mechanics Diagnostic Test”. figshare. https://hdl.handle.net/2134/8779. 
This item was submitted to Loughborough's Institutional Repository (https://dspace.lboro.ac.uk/) by the author and is made available under the following Creative Commons Licence conditions.

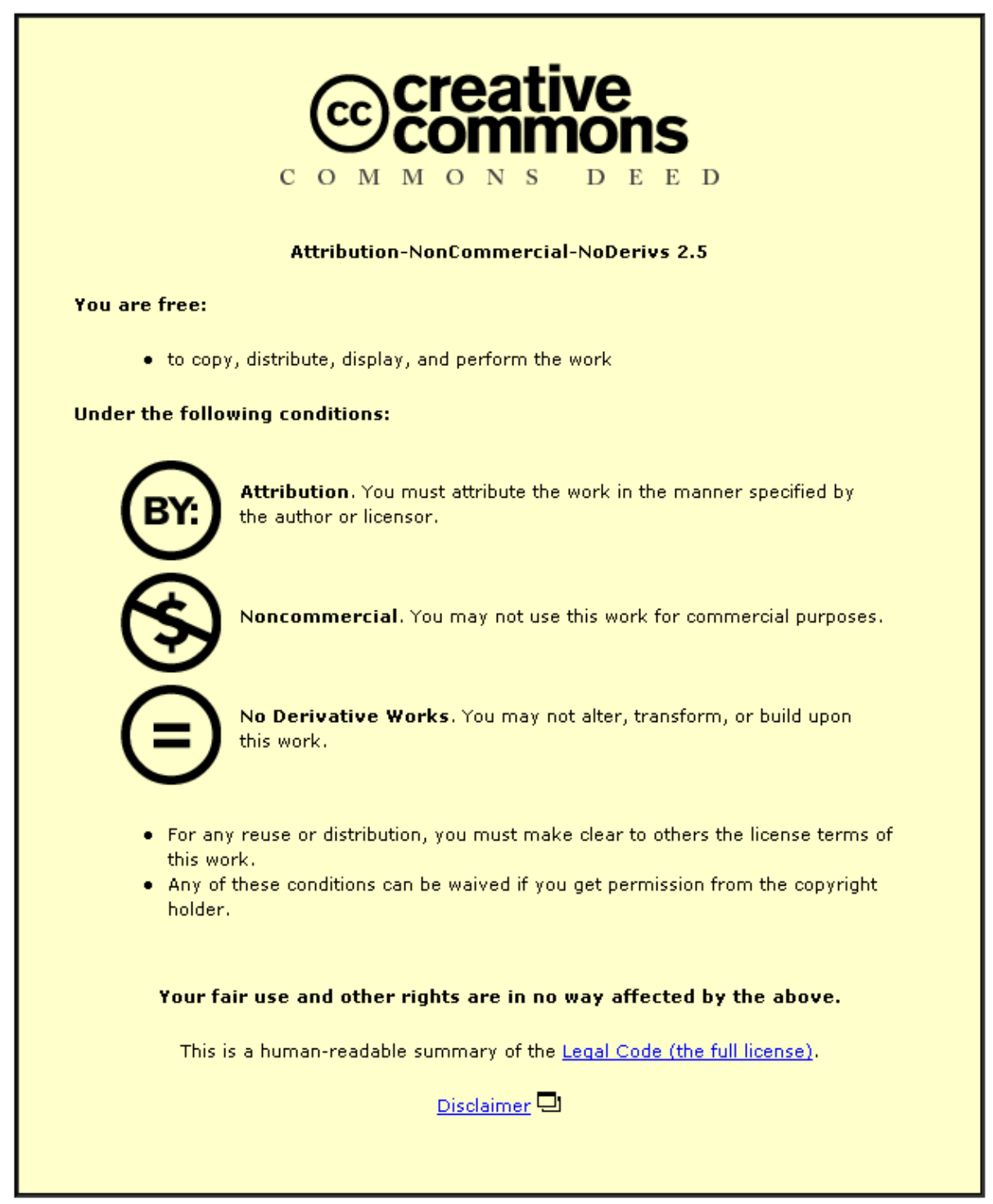

For the full text of this licence, please go to: http://creativecommons.org/licenses/by-nc-nd/2.5/ 


\title{
Identifying what makes a good question in a mechanics diagnostic test
}

\author{
Stephen Lee (corresponding author), Martin C. Harrison \& Carol L. Robinson \\ Mathematics Education Centre, Loughborough University, Leicestershire, LE11 3TU, \\ UK.
}

Email: stephen.lee@mei.org.uk,m.c.harrison@lboro.ac.uk, c.l.robinson@lboro.ac.uk

\begin{abstract}
Many students entering engineering degrees encounter problems with the mathematics contained within such degrees. More recently, research has shown that freshers may have insufficient knowledge of mechanics. In order to assess this, the authors created and administrated a multiple choice mechanics diagnostic test. This paper gives details of the mechanics diagnostic test, and evaluates, using item analysis, how students' performed in the questions and topics assessed by it. Finally, it gives recommendations for devising questions which allow a diagnostic test to discriminate between students.
\end{abstract}

Keywords: Mechanics diagnostic testing, assessment, topics, freshers’ knowledge

\section{Incoming UK engineering students' knowledge of mechanics upon arrival}

It has been widely accepted that there is a continuing 'mathematics problem', which is the insufficient mathematical ability of students entering numerate undergraduate degrees, including engineering. Reports in the last decade, such as: 'Tackling the mathematics problem', (1); 'The changing mathematical background of undergraduate engineers', (2); 'Mathematics matters in engineering', (3); 'Measuring the mathematics problem', (4) and 'Mathematics in the university education of engineers', (5) highlight this. Croft and Grove (6) discuss what initiatives and resources have been developed in recent years to remedy such issues. One example is the mathcentre project whose resource website (www.mathcentre.ac.uk) in the academic year 2005-06 averaged a quarter of a million hits a month.

Recent research, (7), has also shown there to be an issue with incoming engineering students' knowledge of mechanics. Questionnaire responses from over 1000 engineering students at three universities in (7) indicated that almost one third of students had studied little or no mechanics prior to entering university. Similar findings were described in (8). This is an obvious concern given that the majority, if not all, mechanical engineering degrees contain compulsory modules in mechanics in their first year. One of the reasons for students entering university having studied little or no mechanics is, at least in part, due to the changes that have taken place to preuniversity mathematics qualifications (specifically Mathematics A-levels) in recent years. This included a change to all A-levels via 'Curriculum 2000' and a subsequent restructuring of Mathematics A-levels in September 2004. Detail of these changes, with respect to mathematics, can be seen in (9). Indeed, the restructuring in 2004 meant that instead of having the opportunity to study three applied modules, where applied modules include mechanics, statistics and discrete mathematics, alongside the three compulsory pure modules, students can now only study two applied modules 
(alongside the four compulsory pure modules). This means that students who enter university with A-level Mathematics, after September 2006, will have studied only two applied modules and thus at most two modules of mechanics. Indeed, (10) highlighted that from a survey, which included over 13000 students studying Mathematics AS/A-levels, only 13\% of the students were studying the second mechanics module in Mathematics A-levels. (Note. Students studying Further Mathematics are more likely to have studied more mechanics than those who only study Mathematics. Also it is important to recognise that there is compulsory mechanics within A-level Physics, although this is introductory material.))

With such evidence and the associated concerns over engineering students' knowledge of mechanics upon entry to university a mechanics diagnostic test was developed by the authors to review incoming students' knowledge of mechanics. This is detailed and analysed in the next section; this includes use of item analysis and discussion of the distracters used in questions.

For information, a comparison between the number of mechanics modules students had studied in Mathematics A-levels and their mechanics diagnostic test mark can be seen in (11). There it was shown that the more modules of mechanics students had studied the higher, on average, their mechanics diagnostic test mark was.

\section{Mechanics diagnostic test structure and implementation}

Having had prior experience of administrating a mathematics diagnostic test to large groups of students (circa 1000 overall per annum) at Loughborough University and analysing the results, see (12), it was decided to construct a similar mechanics test. Therefore, the mechanics test was to be a paper-based, multiple-choice, Optical Mark Reader (OMR) marked test. In particular, it would focus upon establishing whether students were able to use and apply basic concepts from mechanics.

In the academic year 2003-2004, the examination board OCR included the following topics in their Mechanics 1 (M1) module: Force as a vector, equilibrium of a particle, Newton's laws of motion, linear momentum and kinematics of motion in a straight line. It was found that the mechanics module M1, from other examination boards generally contained similar topics. Subsequently, it was decided to set three questions on each of the five 'Mechanics 1' topics (mentioned previously), although in the end only two questions were set on one of the topics (linear momentum) because there was not much depth to material covered in the topic in the module. These 14 questions formed the basis of the test and were to be the discriminators between students who had studied none or one or more modules of mechanics. As well as these questions, in total eight questions were set on 'Mechanics 2' topics in order to identify those students who had studied a higher number of mechanics modules (the topics included centre of mass, equilibrium of a rigid body, motion of a particle, coefficient of restitution and energy, work and power). Also included were two 'other' questions that would test common student misconceptions in mechanics about what forces act upon a particle at a given time. A copy of the actual mechanics diagnostic test, which has 24 questions in total, can be viewed online at the following address: http://mec.lboro.ac.uk/... [] 
Two example questions 11 and 13 in the mechanics diagnostic test can be seen in Figure 1 . These questions were both answered very well by the students.:-

(It should be noted that the 24 mechanics questions were labelled from 6 to 29 because some background information on the students was collected in questions 1 to 5.)

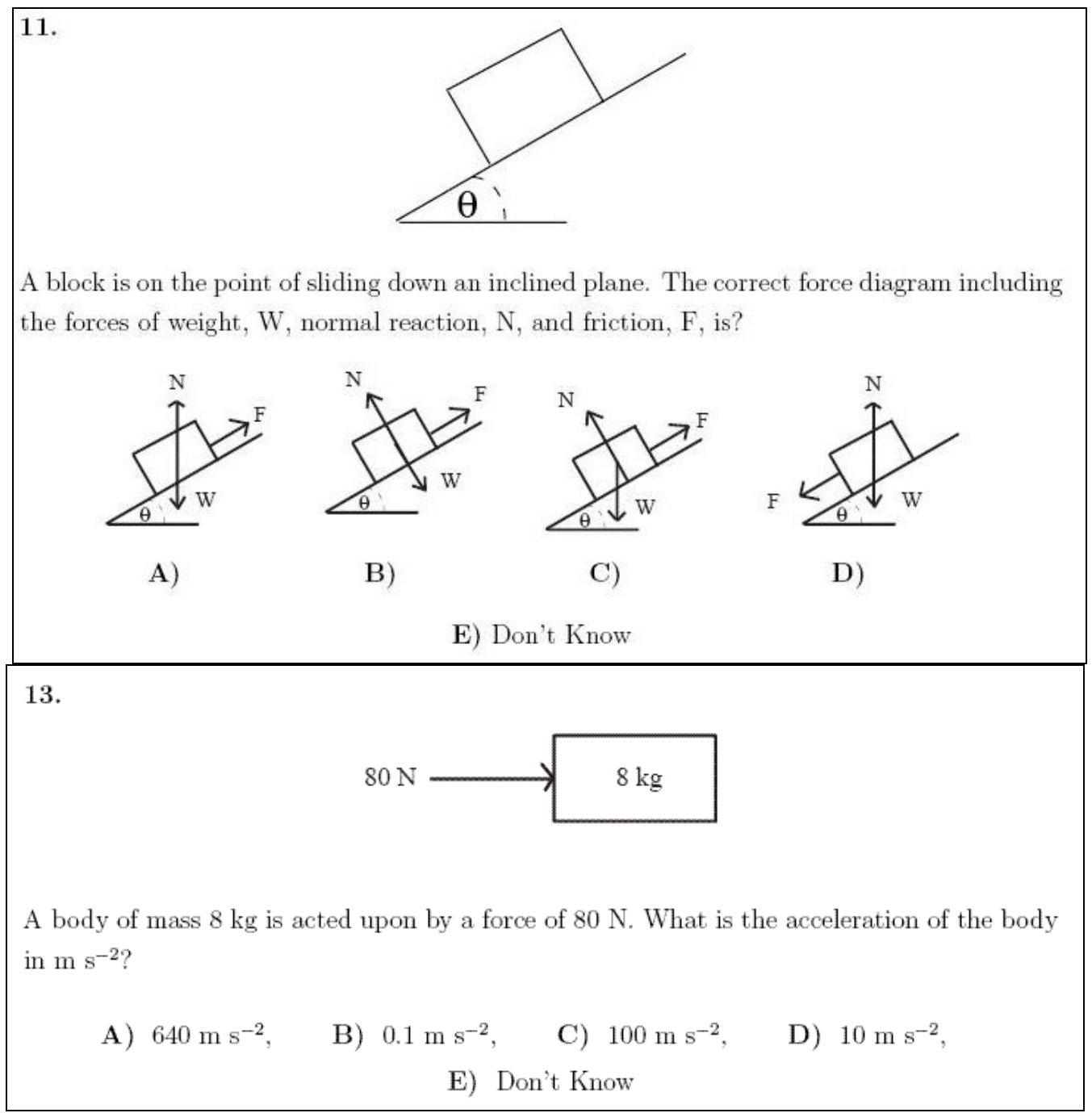

Figure 1 - Example questions (Q11 and Q13) from mechanics diagnostic test, which were found to be answered very well by students.

This shows how the questions were laid out, with multiple-choice answers, including option E of 'Don't Know', which was common to all questions. Students were encouraged to choose this if they did not know how to do the question rather than guess.

Once the test was written it was trialled by three people and then reviewed by $\mathrm{Mr}$ David Holland, the chief mechanics examiner and deputy chairman of the curriculum development body MEI (Mathematics in Education and Industry). Some minor changes were made following the trials and review. Subsequently, several groups of engineering students sat the test upon arrival to university, these included: 
aeronautical, automotive, electrical, mechanical and manufacturing engineering students. Within these groups there were potentially 500 students who would sit the mechanics diagnostic test.

In total 450 engineering students completed the mechanics diagnostic test, which was administrated in a tutorial session in the first week of term in academic year 2004-05. This resulted in a high response rate of $90 \%$ of registered students completing it. The overall average for the mechanics diagnostic test was quite high at 70\%; however this will be discussed in the next section.

\section{Analysis of the mechanics diagnostic test}

As described, the mechanics diagnostic test was created to establish incoming students' knowledge of mechanics upon arrival to university. As this was the first time the mechanics diagnostic test had been administrated it was evaluated in some detail. There are two components to this analysis; firstly a discussion on item analysis and secondly a discussion on the distracters used.

\section{Item analysis}

As described in (13):

Item analysis can indicate which items may be too easy or too difficult and which may fail, for whatever reasons, to discriminate properly between high and low achievers.

There are two primary measures (or indexes) considered in item analysis. These are:

- The index of item difficulty, i.e. how difficult the question is. This is the percentage of students who correctly answered the question.

- The index of discrimination i.e. how the question discriminates between the good (upper 25\%) students and the poor (lower 25\%) students.

The index of discrimination can take values between -1 and 1 . A value between 0 and 1 shows a positive discrimination between the upper and lower groups, whereas a value between 0 and -1 , shows a negative discrimination. (13) discussed the calculations for these measures and produced a table giving an indication of what the values of the index of discrimination represent, see Table 1 . The calculations involved subtracting the performance of the collective group of 'poor' (lower 25\% of) students in a question from the performance of the collective group of 'good' (upper 25\% of) students in the same question.

\begin{tabular}{|l|l|}
\hline Index of Discrimination & Item Evaluation \\
\hline $0.40+$ & Very good items \\
\hline 0.30 to 0.39 & $\begin{array}{l}\text { Reasonably good but possibly subject to } \\
\text { improvement }\end{array}$ \\
\hline 0.20 to 0.29 & $\begin{array}{l}\text { Marginal items, usually needing and } \\
\text { being subject to improvement }\end{array}$ \\
\hline Below 0.19 & $\begin{array}{l}\text { Poor items, to be rejected or improved by } \\
\text { revision }\end{array}$ \\
\hline
\end{tabular}


Table 1 - Index of discrimination - description of values

Table 2 shows the outcome of the two indexes for the 24 questions of the mechanics diagnostic test. For the item difficulty, it can be seen that there is a large range of values, from 17 to 98, although 19 of the 24 questions were correctly answered by more than half of the students (as indicated by an item difficulty value of more than 50).

\begin{tabular}{|c|c|c|}
\hline $\begin{array}{c}\text { Qu. } \\
\text { Number }\end{array}$ & $\begin{array}{c}\text { Item } \\
\text { Difficulty }\end{array}$ & $\begin{array}{c}\text { Index of } \\
\text { Discrimination }\end{array}$ \\
\hline 9 & 98 & 0.06 \\
\hline 15 & 93 & 0.22 \\
\hline 23 & 92 & 0.18 \\
\hline 7 & 91 & 0.25 \\
\hline 11 & 91 & 0.23 \\
\hline 13 & 91 & 0.17 \\
\hline 6 & 89 & 0.26 \\
\hline 19 & 85 & 0.22 \\
\hline 17 & 80 & 0.35 \\
\hline 18 & 78 & 0.49 \\
\hline 16 & 76 & 0.36 \\
\hline 22 & 75 & 0.46 \\
\hline 8 & 73 & 0.47 \\
\hline 12 & 73 & 0.44 \\
\hline 27 & 72 & 0.62 \\
\hline 26 & 68 & 0.55 \\
\hline 29 & 64 & 0.52 \\
\hline 24 & 61 & 0.63 \\
\hline 10 & 58 & 0.71 \\
\hline 25 & 48 & 0.67 \\
\hline 28 & 40 & 0.49 \\
\hline 20 & 39 & 0.53 \\
\hline 14 & 21 & 0.40 \\
\hline 21 & 17 & 0.38 \\
\hline
\end{tabular}

Table 2 - Item difficulty and index of discrimination for the 24 questions of the mechanics diagnostic test

With respect to the index of discrimination, 16 out of the 24 (67\%) questions had a value of 0.30 or above (in fact 0.35 or above), which indicated the questions were reasonably good or very good. The eight questions, which had index of discrimination values below 0.30, were the eight 'easiest' questions as determined by the item difficulty. This indicates that the easiest questions did not discriminate very well between the upper $25 \%$ and lower $25 \%$ of students. Two examples of these questions, firstly Q11, on equilibrium of a particle and secondly Q13, on Newton's laws of motion, are given in Figure 1. Other questions that were answered well were on the 
topics of force as a vector, linear momentum, kinematics of motion in straight line and equilibrium of a rigid body.

Reviewing the individual questions indicated that many of them were answered well, which supports the overall high average of $70 \%$ for the test. There are several possible reasons for this; examining the questions further showed that at least $50 \%$ could be answered with a reasonable knowledge of mathematics, not necessarily mechanics knowledge. It may be that with some of the questions in the early mechanics topics it is inherently possible to answer them correctly using:

- Other mathematics skills, not necessarily mechanics skills, e.g. using trigonometry for calculating forces

- Intuition, e.g. calculating the centre of mass of a simple shape

Another explanation is that nearly all engineering students will have studied A-level Physics as well as A-level Mathematics. Within A-level Physics there are modules that contain material on introductory mechanics. Therefore, it is possible that students could have some experience of mechanics, especially the basics that are covered in M1.

The two simple measures of difficulty and discrimination have given a brief insight into the questions on the diagnostic test. However, as stated in (14), "We recommend that attention be focused on the pattern of responses rather than on the difficulty level or discrimination index." Thus, the pattern of responses is now considered.

\begin{tabular}{|l|l|l|l|l|l|l|}
\hline Qu. 6 & A & B & C & D & E & Unknown \\
\hline High & 0.89 & 0.89 & 98.21 & 0.00 & 0.00 & 0.00 \\
\hline Low & 4.46 & 14.29 & 72.32 & 0.00 & 8.93 & 0.00 \\
\hline ALL & 2.68 & 7.59 & 85.27 & 0.00 & 4.46 & 0.00 \\
\hline
\end{tabular}

Table 3 - High and Low group responses to question six

The students whose score on the mechanics diagnostic test was in the top and bottom $25 \%$ of results for the whole group were separated from the rest. These were labelled as the High and Low groups. Then, for each of these groups the percentage of students in the group who chose each of the five possible answers on each question in the test was collated. An example of this can be seen in Table 3, where $98.21 \%$ of the High group chose the correct answer $\mathrm{C}$ and $72.32 \%$ of the Low group also chose $\mathrm{C}$ for question six. Moreover, $85.27 \%$ of all the students (not just those in the High and Low groups) chose C.

Firstly, in all 24 questions a higher percentage of the High group correctly answered each question, than did from the Low group. This was seen previously by the fact that the discrimination index for all questions was positive. 
Secondly, when considering the questions that were answered less well, comparing the percentage of students in each group that answered the question correctly gives some interesting findings. For example, in question 10, which can be seen in Figure 2, overall $57.56 \%$ of students answered it correctly, with $90.18 \%$ of the High group answering it correctly compared to only $18.75 \%$ of the Low group. Similarly in question 28, which can also be seen in Figure 2, overall 40.44\% of students answered it correctly, with $70.54 \%$ of the High group answering it correctly, compared to only $21.43 \%$ of the Low group. In most instances this was the case for the questions answered comparatively poorly, i.e. questions 14, 20, 21, 24, and 25. In addition, in many of these questions students in the Low group chose option E, which was 'Don't Know' and hence admitted that they didn't know how to answer the question. For example, in question $10,56.25 \%$ of the Low group chose $\mathrm{E}$ and for question 25 , $57.14 \%$ of the Low group chose $\mathrm{E}$.

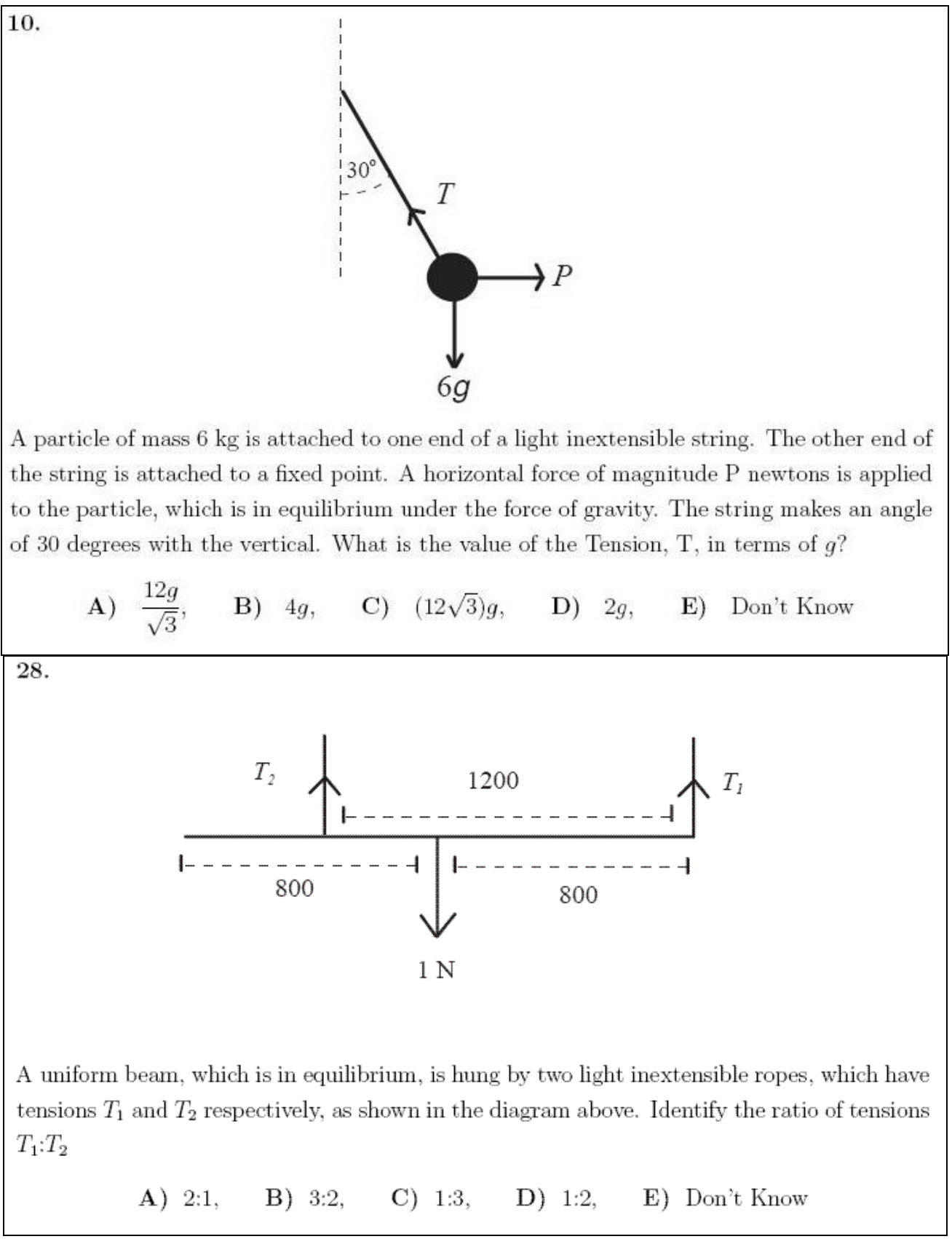


Figure 2 - Questions (Q10 and Q28) that were answered poorly, but which discriminated well between the good and poor performing students.

\section{Distracters}

It is also important when undertaking item analysis to consider how the distracters performed. In 19 out of the 24 questions, over $90 \%$ of the students in the High group answered the question correctly. This meant that there were very few students who chose each of the other distracters. However, in only 10 out of the 24 questions, over $50 \%$ of the students in the Low group answered the question correctly. This meant that a large percentage of students in this group chose one of the distracters or option E signifying that they didn't know how to answer the question. In many questions it was evident that one or sometimes two of the distracters attracted the most (incorrect) responses and this was particularly the case for those students in the High group who incorrectly answered a question. Basically, this indicates that all distracters were not as good as each other. For example, in question 14, which can be seen in Figure 3, $71 \%$ of those that answered the question incorrectly chose option C. Similarly, in question 17, which can also be seen in Figure 3, it was possible to distinguish that $70 \%$ of those who answered the question incorrectly selected answer A, which indicated that the gradient of a displacement-time graph represented acceleration rather than velocity. Thus, by having suitable distracters it is possible to understand what error a student is likely to have made.

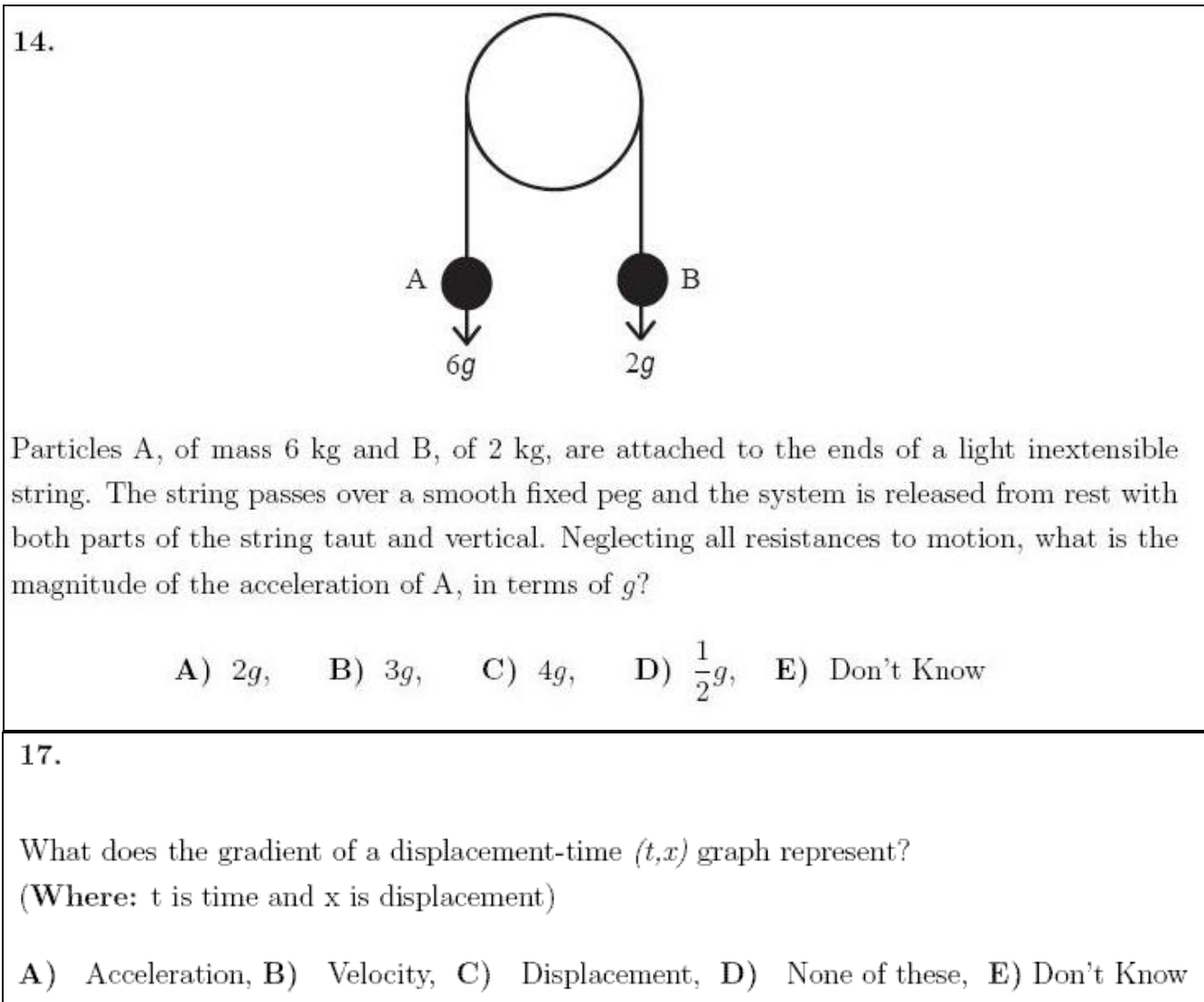
A) $2 g$,
B) $3 g$,
C) $4 g$,
D) $\frac{1}{2} g$,
E) Don't Know

17.

What does the gradient of a displacement-time $(t, x)$ graph represent?

(Where: $\mathrm{t}$ is time and $\mathrm{x}$ is displacement)
A) Acceleration,
B) Velocity,
C) Displacement,
D) None of these,
E) Don't Know

Figure 3 - Questions (Q14 and Q17) in which the majority of incorrect answers were for only one of the distracters. 


\section{Concluding Discussion}

Within this paper, attention was drawn to recent research highlighting incoming students' inadequacies in mathematics and mechanics. Loughborough University, which has in total some 4000 engineering students, has, for a number of years given each intake a mathematics diagnostic test. Following concern over engineering students' knowledge of mechanics in recent years an additional mechanics diagnostic test was trialled and has been reported upon in this paper. The structure and implementation of the test was discussed. Reviewing individual questions highlighted that many of the questions could have been answered without specific knowledge in mechanics, but with a combination of other mathematical skills or intuition.

Overall, the questions in the mechanics diagnostic test have distinguished between the high and low attaining students. The questions enabled it to be seen if students didn't know the answer to the question, which was particularly evident for the lower attaining students. Distracters gave insight into students' misunderstandings, although having three good quality distracters rather then just one or two could have improved questions. When there was little discrimination between students in the High and Low groups, questions were very well answered. It may be that these questions could be made more difficult. The likely effect of this would be to bring down the overall (high) average for the test and produce a higher percentage (greater than 66\%) of good discriminating questions.

With respect to the index of discrimination within the item analysis, 16 out of the 24 (67\%) questions had a value of 0.35 or above, which indicated these questions were reasonably good or very good. The eight questions, which had index of discrimination values below 0.35, were the eight 'easiest' questions as determined by the item difficulty. This indicates that the easiest questions did not discriminate very well between the upper and lower 25\% of students. However, it is inherent in such a test that some questions will be answered well by both students who performed well on the test overall and those that performed less well on the test; otherwise it could be de-motivating for the less well performing students if they cannot answer many of the questions.

One of the most important considerations was the use of distracters in questions. In many situations to aid both revision of topics at the start of a course and to produce lecturing notes of an appropriate nature, then it is very beneficial to understand why a student answered a question incorrectly.

Thus, through reviewing the results of the mechanics diagnostic test and conducting item analysis on it, we are able to offer the following recommendations for devising a good question in a multiple choice mechanics diagnostic test:

- A good question should discriminate between the high and low attaining students.

- A good question should allow students to acknowledge if they do not know the answer.

- A good question should have distracters that are all equally plausible. 
- A good question should have distracters which can offer some insight into what mistake (or misunderstanding) the student had in answering the question.

\section{References}

[1] LMS, Tackling the Mathematics Problem. A joint report of the LMS, IMA and RSS. (1995). Available from < http://www.lms.ac.uk/policy/tackling_maths_prob.pdf> [Accessed October 29th, 2006].

[2] Sutherland, R. and Pozzi, S., The Changing Mathematical Background of Undergraduate Engineers - a review of the issues. The Engineering Council, London, UK. (1995).

[3] IMA, Mathematics Matters in Engineering. The Institute of Mathematics and Its Applications, Southend-on-Sea. (1995).

[4] Hawkes, T. and Savage, M.D., (eds) Measuring the Mathematics Problem. Engineering Council. UK. (2000). Available from $<$ http://www.engc.org.uk/documents/Measuring_the_Maths_Problems.pdf> [Accessed October 29th, 2006].

[5] Kent, P. and Noss, R., Mathematics in the University Education of Engineers. The Ove Arup Foundation, London, UK. (2003).

[6] Croft, A.C. and Grove, M., Mathematics Support - Support for the specialist mathematician and the more able student. MSOR Connections, 6(2), (2006) pp3943.

[7] Robinson, C.L., Harrison, M.C. \& Lee, S. The Mechanics Report Responding to the Changes in the Teaching and Learning of Mechanics in Schools, 2005. Higher Education Academy Engineering Subject Centre. (2005). Available from < http://www.engsc.ac.uk/downloads/resources/mechanics.pdf> [Accessed October 29th, 2006].

[8] Clements D, Prior knowledge of mechanics amongst first year engineering students. In Hibberd, S. and Mustoe, L.R. (eds) Proceedings of the IMA Conference, Mathematical Education of Engineers, 11 - 12 April 2006, Loughborough University, (2006), ISBN 9780905091183 Institute of Mathematics and its Applications.

[9] Porkess, R., The new AS and A-Levels in Mathematics. MSOR Connections, 3(4), (2003). pp12-16.

[10] Lee, S., Harrison, M.C. and Robinson, C.L., Recent changes in A-level Mathematics - is the availability and uptake of mechanics declining yet more? In Hibberd, S. and Mustoe, L.R. (eds) Proceedings of the IMA Conference, Mathematical Education of Engineers, 11 - 12 April 2006, Loughborough University, (2006), ISBN 9780905091183 Institute of Mathematics and its Applications. 
[11] Lee, S., Harrison, M.C. and Robinson, C.L., UK engineering students' knowledge of mechanics upon arrival at university: expectation and reality. Engineering Education - The Journal of the Higher Education Academy Engineering Subject Centre. 1(1), (2006) pp32-38.

[12] Robinson, C.L. and Croft, A.C., Engineering Students - diagnostic testing and follow-up. Teaching Mathematics and its Applications, 22(4), (2003) pp177-181.

[13] Ebel, R. L. and Frisbie, D. A., Essentials of Educational Measurement - 5th Edition. Englewood Cliffs, N.J., Prentice-Hall. (1991).

[14] Case, S. M. and Swanson, D. B., Constructing written test questions for the basic and clinical sciences: Third Edition. (2001) Available from $<$ http://www.nbme.org/PDF/2001iwg.pdf> [Accessed October 29th, 2006]. 